CRYSTALS AND X-RAYS. KathleEN Lonsdale, D.Sc., F.R.S. London: G. Bell \& Sons, 1948, I90 pages. 2 Is.

THIs book is based on a series of lectures which the author gave at University College, London. It is intended to show physicists, chemists and others interested in X-ray crystallography the physical principles which underlie X-ray analysis. It also gives a general survey of its applications. The great contrasts between the standards of severity in different parts of the book rather reminded the reviewer of a typical alpine climb, a feature which is bound to attract the glaciological reader. Let us try to pursue this analogy.

Mrs. Lonsdale starts her climb into the X-ray country on the gentle slopes of the intelligent reader's everyday experience. An easy path leads him through much familiar scenery while sweet flowers in the form of simple parables distract his eyes from the steep cliffs that loom ahead. Whenever he puffs a little under the strain of intellectual effort Mrs. Lonsdale spurs him on with attractive pictures giving him a foretaste of the glorious views to be seen from the summit.

So pleasant is the going through the foothills of this land of $\mathrm{X}$-rays that the climber arrives at the end of the second chapter hardly realizing the distance already covered. But as he enters the third, the ground rapidly changes. Polyhedra of every shape obstruct his progress, his feet get entangled in networks of lattices, at times he has to wind his way up spiral paths, at others to ascend scree-like slopes called glide planes where his foot slips sideways for every step it advances. Crystal Geometry is the name of that passage.

After a short rest, the guide begins the famous traverse through reciprocal space, working her way along the slippery surface of the sphere of reflection. This is tough going for the non-crystallographer, but the lucid diagrams offer plenty of hand and footholds and the rock is always firm. Yet the real test is to come in Chapter V, which shows us how to find atomic and electronic distributions. Though the guide avoids the severest route via the complex exponentials, even her easier way through the real trigonometric functions requires a steady head and a firm grip. The Fourier projections especially seem dangerously exposed; yet Mrs. Lonsdale hardly allows us to take breath before plunging straight into vector space where giddiness is known to have overcome even fully trained physicists. Perhaps this is why her stay there is so short. Or is it because the summit is already in sight?

For with another few steps we arrive at the top of a mountain overlooking a seemingly endless plateau, and the magnificent panorama of the X-ray land unfolds itself before our eyes. We hardly know what to admire more: the varied beauty of the view or our guide's complete and detailed knowledge of it. Texture analysis and crystal dynamics, rocks and dyes, rings and resonance,
fibres and metals, are all explained with lucid brevity.

Though the intricacies of $\mathrm{X}$-ray analysis may be difficult for the non-physicist to follow, the book contains a wealth of interesting material for all who are interested in the atomic structure of things-including ice.

M. F. Perutz (Cambridge)

\title{
GLACIER FLUCTUATION IN THE ALPS
}

THE recession of the Swiss Glaciers proceeded with increased speed during 1947. In his annual report* Dr. P. L. Mercanton points qut that during the winter of $1946 / 47$ the precipitation averaged some three-quarters of normal, while during the six summer months the mean temperature and insolation exceeded their normal values by $3^{\circ} \mathrm{C}$. and 20 per cent respectively. The resulting ablation removed not only the whole of the winter accretion of snow but also a large quantity of the reserves of glacier ice. The only recorded exception was on the Jungfraufirn, where a small surplus of winter snow remained. On the Bristenstock the firn line rose to $2520 \mathrm{~m}$.,

- Die Alpen, Vol. 24, No. 11, 1948, p. 387-94. 